Article

\title{
TiFe Precipitation Behavior and its Effect on Strengthening in Solution Heat-Treated Ti-5Al-3.5Fe During Isothermal Aging
}

\author{
Hye-Jeong Choe ${ }^{1,2}$, Jong Woo Won ${ }^{1, *}$, Yong-Taek Hyun ${ }^{1}$, Ka Ram Lim ${ }^{1}$ and Seog-Young Yoon ${ }^{2}$ \\ 1 Metal Materials Division, Korea Institute of Materials Science, Changwon 51508, Korea; \\ chj030812@kims.re.kr (H.-J.C.); ythyun@kims.re.kr (Y.-T.H.); krlim@kims.re.kr (K.R.L.) \\ 2 School of Materials Science and Engineering, Busan National University, Pusan 46241, Korea; \\ syy3@pusan.ac.kr \\ * Correspondence: jwwon@kims.re.kr; Tel.: +82-55-280-3355
}

Received: 16 October 2018; Accepted: 24 October 2018; Published: 26 October 2018

\begin{abstract}
We investigated the TiFe precipitation behavior of solution heat-treated Ti-5Al-3.5Fe during isothermal aging, quantified the effect of precipitation on strengthening by evaluating the hardness, and compared it to the effect of $\mathrm{Ti}_{3} \mathrm{Al}$ precipitation in Ti-6Al-4V. TiFe precipitates formed both at grain boundaries (GBs) and within the grain matrices. Phase transformation from the $\beta$ to $\alpha$ phase also occurred during isothermal aging; this transformation generated lamellar interphase boundaries between the transformed $\alpha$ phase and remaining $\beta$ phase in prior $\beta$ grains. These interphase boundaries enabled the formation of in-grain TiFe precipitates by acting as a nucleation site. GB precipitation did not require prior $\beta \rightarrow \alpha$ phase transformation to generate nucleation sites (i.e., interphase boundaries), so TiFe precipitation could occur immediately upon isothermal aging. Thus, GB precipitation proceeded more quickly than in-grain precipitation; as a result, precipitates were larger and more spherical at the GBs than in grains. The strengthening behavior exhibited by TiFe precipitation differed obviously from that caused by $\mathrm{Ti}_{3} \mathrm{Al}$ precipitation in Ti-6Al-4V because of its differing precipitation kinetics and related microstructural evolution.
\end{abstract}

Keywords: titanium alloys; precipitates; phase transformation; hardness

\section{Introduction}

Ti-Al-Fe alloys are possible alternatives to the widely used [1-3], but expensive [4], Ti-6Al-4V. The use of Ti-Al-Fe alloys reduces manufacturing costs because $\mathrm{Fe}$ as a $\beta$-stabilizer is less expensive than $\mathrm{V}[5,6]$. Fe also effectively reduces the $\beta$ transus temperature [7], which lowers the necessary processing temperature and further reduces the manufacturing cost. Recent studies showed that the mechanical properties of Ti-Al-Fe alloys are comparable to those of Ti-6Al-4V [8-10]. Representative Ti-Al-Fe alloys include Ti-6Al-2Fe-0.1Si [8], Ti-5Al-2.5Fe [9], and Ti-5Al-1Fe [10].

Aging heat treatment in Ti alloys can increase their strengths by generating precipitates in their microstructures [6]. A typical precipitate of $\mathrm{Al}$-containing $\mathrm{Ti}$ alloys is $\mathrm{Ti}_{3} \mathrm{Al}$, whose precipitation behavior has been extensively investigated using Ti-6Al-4V [11-13]. $\mathrm{Ti}_{3} \mathrm{Al}$ precipitates form during aging heat treatment at temperatures of $<550{ }^{\circ} \mathrm{C}[12,13]$, and their formation causes a significant increase in the material strength [12]. Precipitation also occurs in the Ti-Al-Fe system at $530{ }^{\circ} \mathrm{C}$, but the most common precipitate is $\mathrm{TiFe}$, not $\mathrm{Ti}_{3} \mathrm{Al}$ [14]. TiFe is made by the $\beta$-phase stabilizing element $\mathrm{Fe}$, whereas $\mathrm{Ti}_{3} \mathrm{Al}$ is made by the $\alpha$-phase stabilizing element $\mathrm{Al}$; therefore, the precipitation characteristics of TiFe and the resultant strengthening in Ti-Al-Fe are expected to differ from those of $\mathrm{Ti}_{3} \mathrm{Al}$ precipitation in Ti-6Al-4V. Understanding precipitation behavior is essential for the design of 
appropriate aging heat-treatment conditions. However, TiFe precipitation behavior in Ti-Al-Fe alloys remains poorly understood.

In this work, we investigated the TiFe precipitation behavior of a Ti-Al-Fe system during isothermal aging and evaluated the material hardness to quantify the effect of precipitation on strengthening. We found that the strengthening behavior of TiFe precipitation in the Ti-Al-Fe system differed significantly from that of $\mathrm{Ti}_{3} \mathrm{Al}$ precipitation in Ti-6Al-4V. The difference may arise from differing precipitation kinetics and related microstructural evolution.

\section{Materials and Methods}

A Ti-5Al-3.5Fe alloy ingot produced by induction skull melting was used in this work. To break up solidification structures, the ingot was forged at $1100{ }^{\circ} \mathrm{C}$ in the $\beta$-phase field and then hot-rolled at $930^{\circ} \mathrm{C}$ in the $(\alpha+\beta)$-phase field; the processing temperatures were set with reference to the equilibrium phase diagram of the alloy (Figure 1). The rolled material was solution heat-treated by water-quenching from $950{ }^{\circ} \mathrm{C}$ in the $(\alpha+\beta)$-phase field; the resulting material was defined as the initial material. To investigate TiFe precipitation evolution during aging, the initial material was heat-treated at $500{ }^{\circ} \mathrm{C}$, at which temperature TiFe can form (Figure 1).

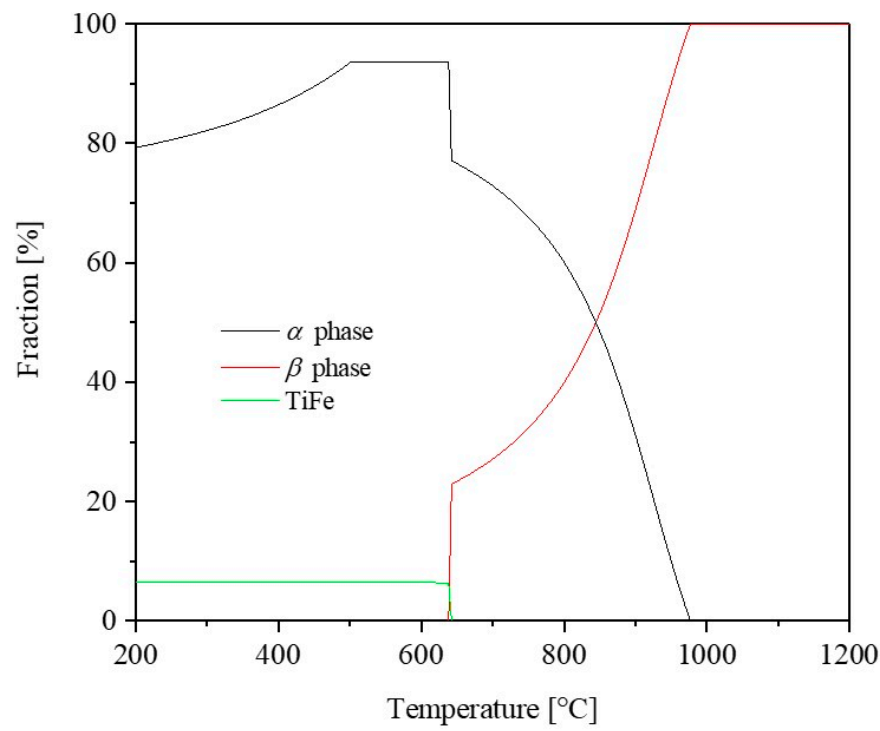

Figure 1. Equilibrium phase information of Ti-5Al-3.5Fe alloy used in this work as a function of temperature, showing possible phases and their fraction; this result was obtained by JMatPro-v8 calculation with Ti database.

The microstructures were examined by scanning electron microscopy (SEM, model: JSM-7001F, JEOL, Tokyo, Japan) at an acceleration voltage of $20 \mathrm{kV}$ and by transmission electron microscopy (TEM, model: JEM 2100, JEOL, Tokyo, Japan) at an acceleration voltage of $200 \mathrm{kV}$. For SEM measurement, the sample surface was mechanically polished and chemically etched using a solution of $96 \mathrm{~mL} \mathrm{H}_{2} \mathrm{O}$ + $2 \mathrm{~mL} \mathrm{HNO}_{3}+2 \mathrm{~mL}$ HF. TEM samples were prepared using a twin-jet electro-polisher (model: Tenupol-5, STRUERS, Cleveland, OH, USA) in a solution of $100 \mathrm{~mL} \mathrm{HClO}_{4}+900 \mathrm{~mL} \mathrm{CH}_{3} \mathrm{OH}$. Crystal structures of different phases were determined by $\mathrm{X}$-ray diffraction (XRD) with $\mathrm{Cu} \mathrm{K} \alpha$ radiation (model: Max-2500VL, Rigaku, The woodlands, TX, USA). Hardness was evaluated using a micro-Vickers tester (model: FM-700, Future-Tech, Kanagawa, Japan).

\section{Results}

The initial material that had been water-quenched (i.e., solution heat-treated) from the $(\alpha+\beta)$-phase region showed that equiaxed $\beta\left(\beta_{\mathrm{R}}\right)$ grains were retained in the microstructure (Figure $2 \mathrm{a}$ ). In $\alpha+\beta \mathrm{Ti}$ alloys, thin $\alpha$-phase lath structures are generally formed inside $\beta$-phase grains during water-quenching 
from high temperatures [15-19]. The Fe in the Ti-5Al-3.5Fe alloy has 2.5 times the $\beta$-phase stabilization ability of $\mathrm{V}$ in Ti-6Al-4V [8]. Thus, the Ti-5Al-3.5Fe alloy underwent almost no $\beta \rightarrow \alpha$ phase transformation during solution heat treatment and the initial material shows equiaxed $\beta_{R}$ grains. We also observed primary $\alpha$-phase $\left(\alpha_{\mathrm{p}}\right)$ grains because the initial material had been cooled from the $(\alpha+\beta)$-phase region.
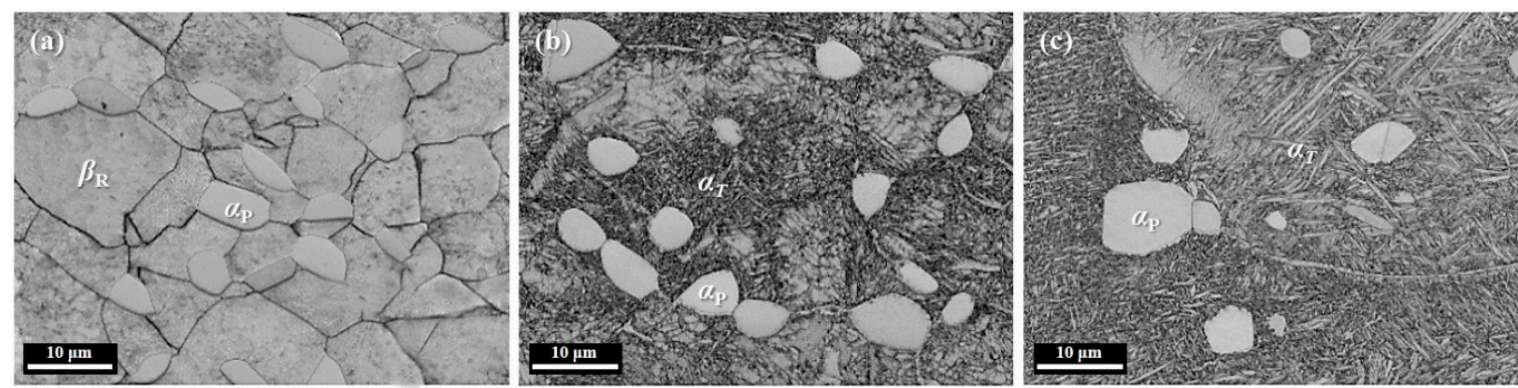

Figure 2. SEM images of Ti-5Al-3.5Fe alloy. (a) Initially, (b) after aging for $10 \mathrm{~h}$, and (c) after aging for $100 \mathrm{~h}$, at $500{ }^{\circ} \mathrm{C} ; \alpha_{\mathrm{P}}$ : primary $\alpha$ phase; $\beta_{\mathrm{R}}$ : retained $\beta$ phase; $\alpha_{\mathrm{T}}: \alpha$ phase transformed from retained $\beta$ phase.

The microstructure was significantly changed by isothermal aging. In the material aged for $10 \mathrm{~h}$ (Figure 2b), an $\alpha$-phase lath structure was developed inside the $\beta_{\mathrm{R}}$ grains; this change indicates the $\beta$ $\rightarrow \alpha$ phase transformation. As the aging duration was increased to $100 \mathrm{~h}$, the $\alpha$-phase laths became thickened (Figure 2c). In contrast, the $\alpha_{\mathrm{p}}$-phase grains showed no changes during heat treatment (Figure $2 \mathrm{~b}, \mathrm{c}$ ). The $\beta \rightarrow \alpha$ phase transformation is also verified by XRD patterns (Figure 3 ). The initial material showed very strong peaks of the $\beta$ phase, which confirm that its microstructure was mainly the $\beta_{R}$ phase; weak peaks of the $\alpha$ phase were due to the presence of $\alpha_{\mathrm{p}}$ grains. In the materials aged for both 10 and $100 \mathrm{~h}$, however, the peaks of the $\beta$ phase almost completely disappeared and new peaks of the $\alpha$ phase developed. This observation confirms that aging heat treatment induced $\beta \rightarrow \alpha$ phase transformation. A slight shift in the XRD peaks was also observed as the aging proceeded (Figure 3 ). This phenomenon was because a significant lattice distortion in the initial material due to rapid cooling (i.e., water quenching) was relieved by $\beta \rightarrow \alpha$ phase transformation and TiFe precipitation that occurred during aging.

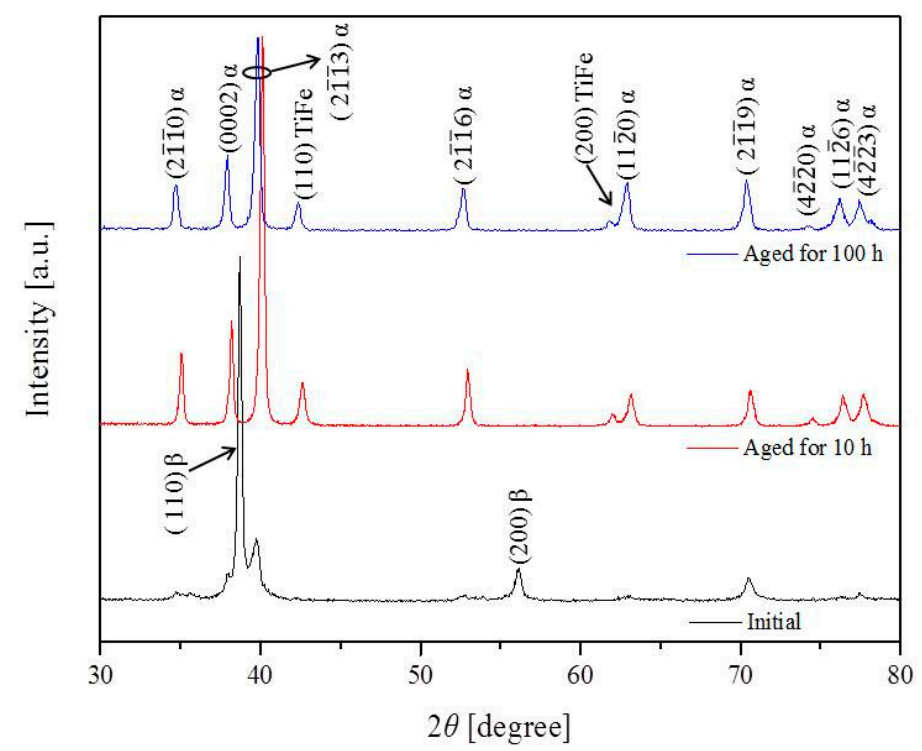

Figure 3. XRD patterns of initial Ti-5Al-3.5Fe alloy and alloy after aging at $500{ }^{\circ} \mathrm{C}$ for 10 or $100 \mathrm{~h}$. 
The XRD patterns of the aged material also showed TiFe peaks (Figure 3), which indicates TiFe precipitate formation in the microstructure. TiFe precipitates were not clearly visible in the SEM image (Figure 2) because they are very fine $(<100 \mathrm{~nm}[14])$. TiFe precipitates were examined in detail using TEM. In the material aged for $10 \mathrm{~h}$ (Figure $4 \mathrm{a})$, numerous and very fine $(15-90 \mathrm{~nm})$ TiFe precipitates were formed throughout the microstructure, both at grain boundaries (GBs) and within grains (Figure 4b). GB precipitates (Figure 4c) and in-grain precipitates (Figure 4d) both had a body-centered cubic (BCC) crystal structure, which is characteristic of TiFe [20]. The GB precipitates were relatively spherical, but most in-grain precipitates were rectangular cuboids. The matrix showed strong hexagonal close-packed diffraction patterns (Figure 4e), which is consistent with the mostly $\alpha$-phase matrix. Isothermal aging for $100 \mathrm{~h}$ increased the size of the spherical GB precipitates substantially, whereas in-grain precipitates increased moderately in size and became increasingly spherical (Figure 5a). The number of the precipitates was considerably decreased from $140 / \mu \mathrm{m}^{2}$ in the material aged for $10 \mathrm{~h}$ (Figure $4 \mathrm{a}$ ) to $37 / \mu \mathrm{m}^{2}$ in the material aged for $100 \mathrm{~h}$ (Figure 5a). The matrix was almost completely transformed to the $\alpha$ phase (Figure $5 b$ ).
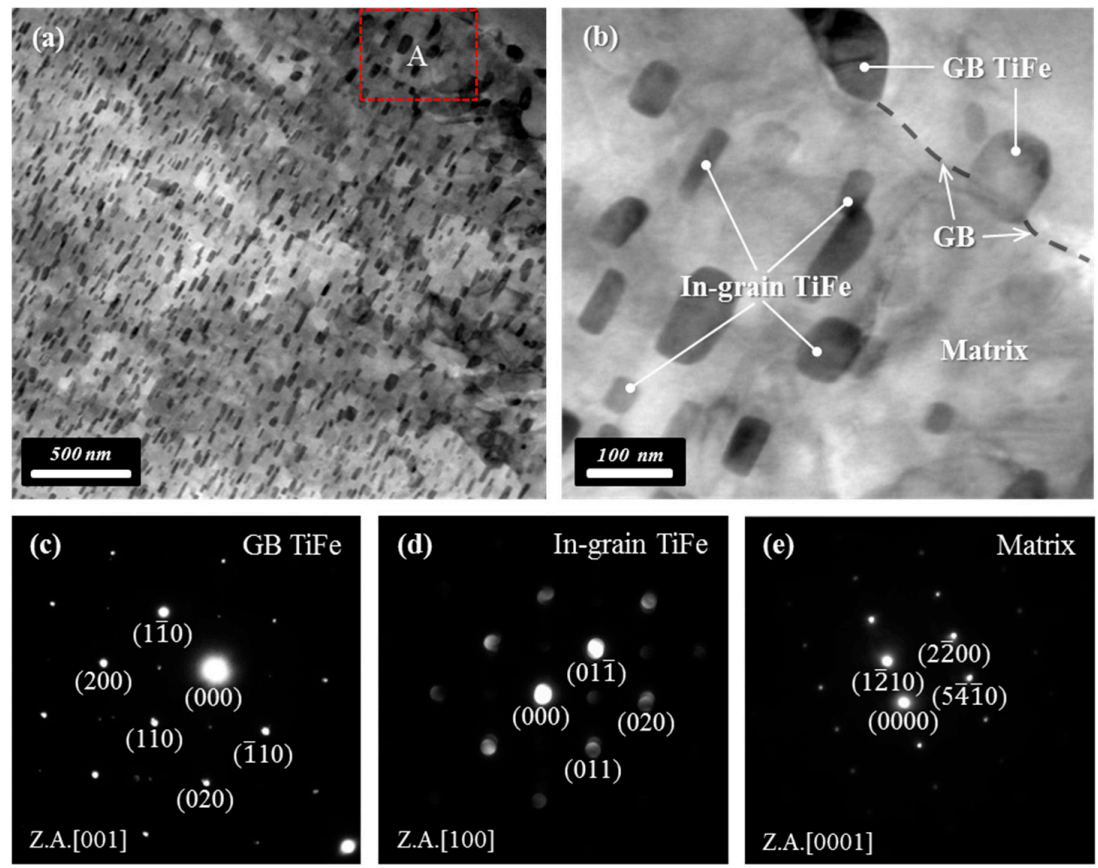

Figure 4. TEM analysis results of Ti-5Al-3.5Fe alloy after aging for $10 \mathrm{~h}$. (a) Bright-field image, (b) magnification of the area $\mathrm{A}$ indicated in (a), and (c-e) diffraction patterns of three important phases observed in (b).
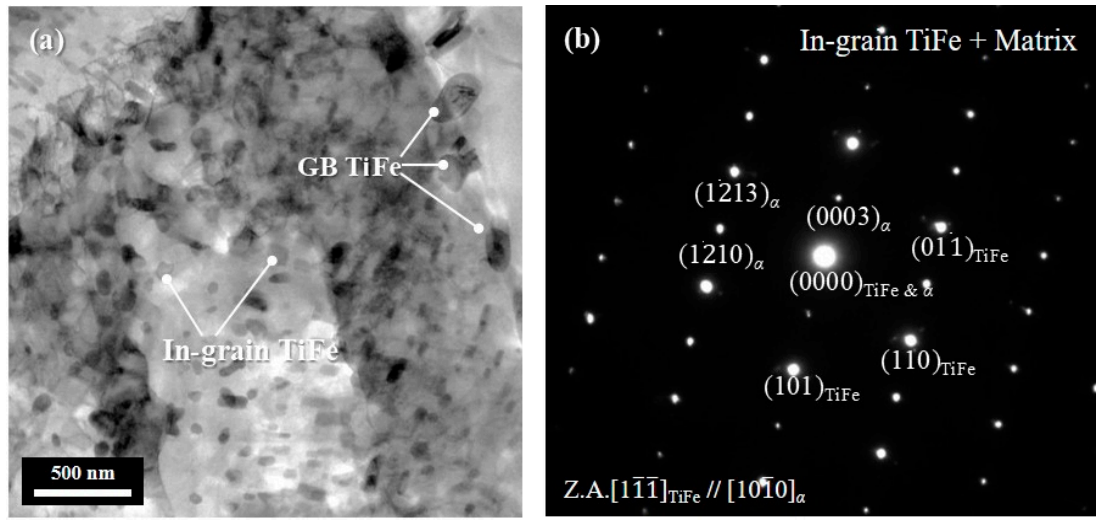

Figure 5. TEM analysis results of Ti-5Al-3.5Fe alloy after aging for $100 \mathrm{~h}$. (a) Bright-field image and (b) corresponding diffraction patterns. 
TiFe precipitation clearly affected the Vickers hardness $H_{\mathrm{V}}$ of the alloy (Figure 6). The initial material had $H_{\mathrm{V}} \sim 450$; this was increased to $\sim 510$ with $10 \mathrm{~h}$ aging and rapidly decreased for $>10 \mathrm{~h}$ aging. The material showed $H_{\mathrm{V}} \sim 400$ after $100 \mathrm{~h}$ aging. This nonlinear trend in precipitation strengthening clearly differs from that of Ti-6Al-4V (Figure 6, [21]).

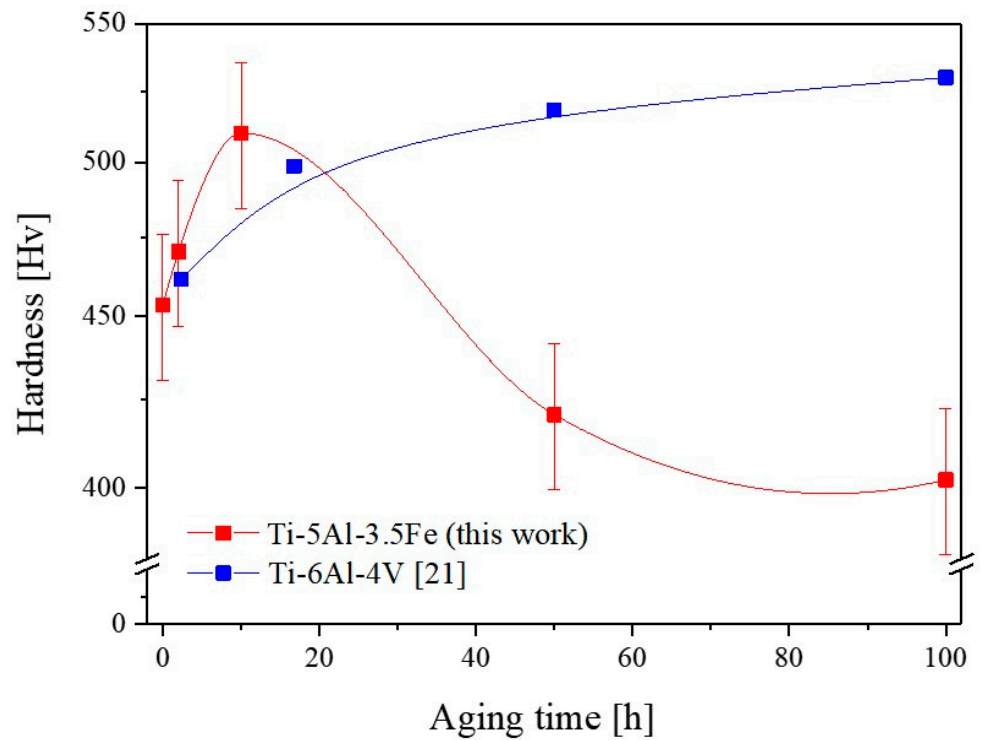

Figure 6. Variation in average hardness with aging time; the value at aging time $=0 \mathrm{~h}$ indicates the hardness for the initial material. Error bars indicate the standard deviations. A result of Ti-6Al-4V [21] is presented for comparison.

\section{Discussion}

Precipitation generally occurs at microstructural defects such as GBs and interphase boundaries because they act as nucleation sites for precipitation [22,23]. However, our results showed that TiFe precipitates formed not only at GBs, but also inside the grain matrix in which no preferential nucleation sites had been observed. XRD (Figure 3) and TEM (Figures 4 and 5) results showed that the $\beta_{\mathrm{R}}$ phase in the initial material was transformed to $\alpha$ phase during aging. The transformation yields a lamellar structure comprising transformed $\alpha$ phase and remaining $\beta$ phase inside prior $\beta$ grains $[24,25]$; the boundaries between these phases are well-known nucleation sites for precipitation [22]. Accordingly, we expect that the $\beta \rightarrow \alpha$ phase transformation occurred before in-grain precipitation, generating such a lamellar structure, and that the boundaries enabled the formation of in-grain TiFe precipitates by acting as a nucleation site. This expectation is supported by the observation that in-grain TiFe precipitates formed as if they were aligned at lamellar interphase boundaries (Figure 4). However, lamellar interphase boundaries were uncommon in the material aged for $10 \mathrm{~h}$ (Figure 4e) and almost completely disappeared after aging for $100 \mathrm{~h}$ (Figure 5b). This microstructural evolution may occur because, during TiFe precipitation, the $\beta$-stabilizing Fe atoms are expelled from the remaining $\beta$ phase and move to the precipitates. Thus, the stability of the remaining $\beta$ phase decreased as precipitation proceeded, and as a consequence, additional $\beta \rightarrow \alpha$ phase transformation occurred, so the remaining $\beta$ phase was converted to the $\alpha$ phase and the interphase boundaries were eliminated.

The morphology of in-grain TiFe precipitates changed as precipitation proceeded (Figures $4 \mathrm{a}$ and 5a). In-grain TiFe precipitates were mostly cuboid (Figure 4a,b) in the material aged for $10 \mathrm{~h}$; this shape implies high coherency between the precipitates and matrix [26]. Maintaining a high coherency between different phases can minimize the free energy of the entire system by lowering the interphase boundary energy [26]. In this case, precipitates tend to grow in a shape similar to their crystal structure [27]. The in-grain precipitates may have formed cuboid shapes because they preferentially grew in a particular crystallographic direction $(<110>$ in the BCC structure [28]). 
However, as precipitates grew further, the misfit strain required to maintain the coherency was increased, so eventually, the coherency failed and precipitates formed spherical shapes that reduced the misfit strain [26]; thus, large in-grain precipitates were spherical after $100 \mathrm{~h}$ aging (Figure 5a).

During aging, GB precipitation proceeded more quickly than in-grain precipitation. After $10 \mathrm{~h}$ aging (Figure 4b), GB precipitates were more spherical and larger than in-grain precipitates. In the material aged for $100 \mathrm{~h}$, the GB precipitates had grown more significantly than the in-grain precipitates (Figure 5a). Unlike in-grain precipitation, GB precipitation did not require prior $\beta \rightarrow \alpha$ phase transformation to create nucleation sites (i.e., interphase boundaries); therefore, GB precipitation could occur immediately upon isothermal aging. GBs permitted faster Fe diffusion for TiFe precipitation than the lamellar interphase boundaries did [29,30]; this difference further accelerated GB precipitation.

In the Ti-5Al-3.5Fe alloy tested, the Vickers hardness $H_{\mathrm{V}}$ increased significantly for the first $10 \mathrm{~h}$ of aging at $500{ }^{\circ} \mathrm{C}$, compared to the hardness of Ti-6Al-4V (Figure 6). This result indicates that precipitation strengthening occurred and was greater in Ti-5Al-3.5Fe than in Ti-6Al-4V for $10 \mathrm{~h}$ aging. The number of individual precipitates is an important factor in determining the degree of precipitation strengthening [31,32]. During aging at $500{ }^{\circ} \mathrm{C}$ for $10 \mathrm{~h}$, numerous TiFe precipitates $\left(140 / \mathrm{\mu m}^{2}\right)$ formed in the Ti-5Al-3.5Fe alloy (Figure $4 \mathrm{a})$, whereas a limited number $\left(\sim 16 / \mu \mathrm{m}^{2}\right)$ of $\mathrm{Ti}_{3} \mathrm{Al}$ precipitates formed

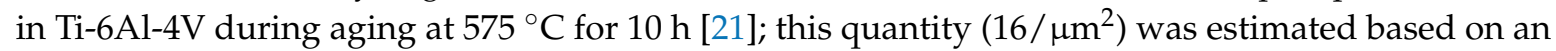

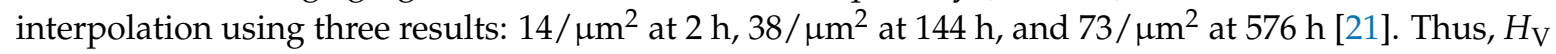
increased more rapidly in Ti-5Al-3.5Fe than in Ti-6Al-4V. More numerous TiFe precipitates may have formed because, in the Ti matrix, Fe atoms have diffusivities 33 times higher than $\mathrm{Al}$ atoms [33]. The fast Fe diffusion facilitated Fe clustering and thus accelerated the kinetics of TiFe precipitation, permitting the nucleation of numerous TiFe precipitates during relatively brief aging.

However, the number of TiFe precipitates considerably decreased in Ti-5Al-3.5Fe after $100 \mathrm{~h}$ aging (Figure 5a). This phenomenon occurred because the precipitation proceeded mainly by the coalescence of preformed precipitates rather than by the nucleation of new precipitates, as a thermodynamically driven process to lower the total free energy of the system by reducing the number of interphase boundaries [26]. Thus, the present alloy showed a rapid reduction in hardness at aging durations of $>10 \mathrm{~h}$ (Figure 6). In addition, considering that interphase boundaries increase the strength of $\alpha+\beta \mathrm{Ti}$ alloys [34], the disappearance of the remaining $\beta$ phase after $100 \mathrm{~h}$ aging may have contributed to the decreased hardness. In contrast, the number of $\mathrm{Ti}_{3} \mathrm{Al}$ precipitates in $\mathrm{Ti}-6 \mathrm{Al}-4 \mathrm{~V}$ increased even during aging heat treatment over $100 \mathrm{~h}$ [21], possibly because the relatively slow kinetics of $\mathrm{Ti}_{3} \mathrm{Al}$ precipitation extended the period during which nucleation-dominant precipitation occurred, compared to the case of TiFe precipitation. Moreover, in Ti-6Al-4V, the remaining $\beta$ phase is stable during aging [21] because its major precipitate $\left(\mathrm{Ti}_{3} \mathrm{Al}\right)$ is made not by the $\beta$-phase stabilizing element $\mathrm{V}$, but by the $\alpha$-phase stabilizing element $\mathrm{Al}$; therefore, strengthening by lamellar interphase boundaries can occur. The results indicate that Ti-5Al-3.5Fe has an optimal aging time to maximize precipitation strengthening. This possibility should be evaluated in other Ti-Al-Fe alloys.

\section{Conclusions}

This work investigated TiFe precipitation behavior in solution heat-treated Ti-5Al-3.5Fe during isothermal aging at $500{ }^{\circ} \mathrm{C}$, and compared this alloy's hardness to that of Ti-6Al-4V to quantify the effect of TiFe precipitation on strengthening. TiFe precipitates were formed at GBs and within the grain matrix. During the aging of Ti-5Al-3.5Fe, the $\beta \rightarrow \alpha$ phase transformation generated a lamellar structure composed of transformed $\alpha$ phase and remaining $\beta$ phase in prior $\beta$ grains. These interphase boundaries enabled the formation of in-grain TiFe precipitates by acting as a nucleation site. GB precipitation did not require prior $\beta \rightarrow \alpha$ phase transformation to create nucleation sites and thus could occur immediately; therefore, GB precipitation proceeded more quickly than in-grain precipitation. As a result, GB precipitates were larger and more spherical than in-grain precipitates. The alloy hardness increased by TiFe precipitation strengthening with $\leq 10 \mathrm{~h}$ aging, but rapidly decreased with longer aging. This precipitation strengthening behavior differed from that 
caused by $\mathrm{Ti}_{3} \mathrm{Al}$ precipitation in $\mathrm{Ti}-6 \mathrm{Al}-4 \mathrm{~V}$, where the hardness was moderately increased even for prolonged aging $>100 \mathrm{~h}$. This difference may occur because Fe has a much higher diffusivity than $\mathrm{Al}$ in the Ti matrix, thus affecting the kinetics of TiFe precipitation. The present work provides a deeper understanding of TiFe precipitation behavior, and may guide the design of optimized aging heat-treatment conditions for Ti-Al-Fe alloys.

Author Contributions: H.J.C., J.W.W., and Y.T.H. suggested the research idea and designed the experiments. H.J.C and J.W.W. performed the experiments. All the authors analyzed the data. H.J.C. and J.W.W. wrote the manuscript.

Funding: This work was funded by the Ministry of Trade, Industry and Energy (Republic of Korea) through the "Materials/Components Technology Development Program (10050608)".

Acknowledgments: The authors are thankful to Gyeong Ryeong Bak for her assistance in TEM measurements.

Conflicts of Interest: The authors declare no conflict of interest.

\section{References}

1. Boyer, R.R. An overview on the use of titanium in the aerospace industry. Mater. Sci. Eng. A 1996, 213, 103-114. [CrossRef]

2. Peters, M.; Henptenmacher, J.; Kumpfert, J.; Leyens, C. Structure and Properties of Titanium and Titanium Alloys. In Titanium and Titanium Alloys-Fundamentals and Application; Leyens, C., Peters, M., Eds.; Wiley-VCH: Cologne, Germany, 2003; p. 22.

3. Niinomi, M. Mechanical properties of biomedical titanium alloys. Mater. Sci. Eng. A 1998, 243, $231-236$. [CrossRef]

4. Koike, J.; Shimoyama, Y.; Ohnuma, I.; Okamura, T.; Kainuma, R.; Ishida, K.; Maruyama, K. Stress-induced phase transformation during superplastic deformation in two-phase Ti-Al-Fe alloy. Acta Mater. 2000, 48, 2059-2069. [CrossRef]

5. Colleen, J.; Tomus, D.; Gibson, M.A. The role of microstructure in the mechanical behavior of Ti-1.6wt.\%Fe alloys containing O and N. Mater. Sci. Eng. A 2011, 528, 4899-4909. [CrossRef]

6. Fujii, H. Strengthening of $\alpha+\beta$ titanium alloys by thermomechanical processing. Mater. Sci. Eng. A 1998, 243, 103-108. [CrossRef]

7. Fujii, H.; Maeda, T. Titanium alloys developed by Nippon steel \& Sumitomo metal corporation. Nippon Steel Tech. Rep. 2014, 106, 16-21.

8. Boyer, R.; Welsch, G.; Collings, E.W. Materials Properties Handbook: Titanium Alloys, 4th ed.; ASM International: Novelty, OH, USA, 2007; p. 682.

9. Ellingsen, J.E.; Lyngstadaas, S.P. Bio-Implant Interface-Improving Biomaterials and Tissue Reactions; CRC Press: Boca Raton, FL, USA, 2003; pp. 194-195.

10. Chan, K.S.; Koike, M.; Johnson, B.W.; Okabe, T. Modeling of alpha-case formation and its effects on the mechanical properties of Titanium Alloy castings. Metall. Mater. Trans. A 2008, 39, 171-180. [CrossRef]

11. Lutjering, G. Influence of processing on microstructure and mechanical properties of $(\alpha+\beta)$ titanium alloys. Mater. Sci. Eng. A 1998, 243, 32-45. [CrossRef]

12. Lee, D.G.; Lee, S.; Lee, C.S. Quasi-static and dynamic deformation behavior of Ti-6Al-4V alloy containing fine $\alpha_{2}-\mathrm{Ti}_{3} \mathrm{Al}$ precipitates. Mater. Sci. Eng. A 2004, 366, 25-37. [CrossRef]

13. Lunt, D.; Busolo, T.; Fonseca, Q.D.; Preuss, M. Effect of nanoscale $\alpha_{2}$ precipitation on strain localization in a two-phase Ti-alloy. Acta Mater. 2017, 129, 72-82. [CrossRef]

14. Lee, S.W.; Kim, K.M.; Park, C.H.; Hong, J.K.; Yeom, J.T.; Shih, D.S. Effects of TiFe intermetallic compounds on the tensile behavior of Ti-4Al-4Fe-0.25Si alloy. Metall. Mater. Trans. A 2017, 48, 561-567. [CrossRef]

15. Xia, J.Y.; Chai, L.J.; Wu, H.; Zhi, Y.; Gou, Y.N.; Huang, W.J.; Guo, N. EBSD study of microstructural and textural changes of hot-rolled Ti-6Al-4V sheet after annealing at $800{ }^{\circ} \mathrm{C}$. Acta Metall. 2018, 31, 1215-1223. [CrossRef]

16. Chong, Y.; Bhattacharjee, T.; Yi, J.; Shibata, A.; Tsuji, N. Mechanical properties of fully martensite microstructure in Ti-6Al-4V alloy transformed from refined beta grains obtained by rapid heat treatment (RHT). Scr. Mater. 2017, 138, 66-70. [CrossRef]

17. Salvador, C.A.; Lopes, E.S.; Ospina, C.A.; Caram, R. Orthorhombic martensite formation upon aging in a Ti-30Nb-4Sn alloy. Mater. Chem. Phys. 2016, 183, 238-246. [CrossRef] 
18. Jiang, X.J.; Jing, R.; Ma, M.Z.; Liu, R.P. The orthorhombic $\alpha^{\prime \prime}$ martensite transformation during water quenching and its influence on mechanical properties of Ti-41Zr-7.3Al alloy. Intermetallics 2014, 52, 32-35. [CrossRef]

19. Mayer, M.; Petersmann, M.; Fischer, F.D.; Clemens, H.; Waitz, T.; Antretter, T. Experimental and theoretical evidence of displacive martensite in an intermetallic Mo-containing $\gamma$-TiAl based alloy. Acta Mater. 2016, 115, 242-249. [CrossRef]

20. Ijiri, M.; Okumura, A.; Ishikawa, T.; Kadowaki, K.; Takemoto, Y. Microstructure of Ti-4Al-7Al alloy quenched in a salt bath after solution treatment. J. Jpn. Inst. Met. Mater. 2016, 80, 691-696. [CrossRef]

21. Carreon, H.; Ruiz, A.; Santovena, B. Study of aging effects in a Ti-6Al-4V alloy with widmanstatten and equiaxed microstructures by non-destructive means. AIP Conf. Proc. 2014, 1581, 739-745.

22. Sharma, G.; Ramanujan, R.V.; Tiwari, G.P. Interphase precipitation in $\gamma$-TiAl alloy. Mater. Sci. Eng. A 1999, 269, 21-25. [CrossRef]

23. Dong, R.; Li, J.; Kou, H.; Fan, J.; Tang, B.; Sun, M. Precipitation behavior of $\alpha$ phase during aging treatment in a $\beta$-quenched Ti-7333. Mater. Charact. 2018, 140, 275-280. [CrossRef]

24. Abdalla, A.O.; Amrin, A.; Muhammad, S.; Hanim, M.A. Effect of heat treatment parameters in the microstructure and microhardness of Ti-6Al-4V alloy. AIP Conf. Proc. 2017, 1865, 030001. [CrossRef]

25. Jing, R.; Liang, S.X.; Liu, C.Y.; Ma, M.Z.; Liu, R.P. Aging effects on the microstructures and mechanical properties of the Ti-20Zr-6.5Al-4V alloy. Mater. Sci. Eng. A 2013, 559, 474-479. [CrossRef]

26. David, A.P.; Kenneth, E.E.; Mohamed, Y.S. Phase Transformations in Metals and Alloys; CRC Press: Boca Raton, FL, USA, 2009; pp. 276-283.

27. Yi, X.; Meng, X.; Cai, W.; Zhao, L. Larger strain recovery characteristics of Ti-Hf shape memory alloy composite under compression. Scr. Mater. 2018, 153, 90-93. [CrossRef]

28. Celotto, S. TEM study of continuous precipitation in Mg-9wt\%Al-1wt\%Zn alloy. Acta Mater. 2000, 48, 1775-1787. [CrossRef]

29. Herzig, C.; Mishin, Y.; Divinski, S. Bulk and interface boundary diffusion in group IV Hexagonal close-packed metals and alloys. Metall. Mater. Trans. A 2002, 33, 765-775. [CrossRef]

30. Aksyonov, D.A.; Lipnitskii, A.G. Solubility and grain boundary segregation of iron in hep titanium: A computational study. Comput. Mater. Sci. 2017, 137, 266-272. [CrossRef]

31. Yuan, Y.; Liu, Z.G.; Liu, X.N.; Meng, X.K. The precipitation reaction in a Ag-modified TiAl based intermetallic, as studied by TEM. J. Alloys Compd. 2005, 399, 126-131. [CrossRef]

32. Miao, J.; Sun, W.; Klarner, A.D.; Luo, A.A. Interphase boundary segregation of silver and enhanced precipitation of $\mathrm{Mg}_{17} \mathrm{Al}_{12}$ phase in a Mg-Al-Sn-Ag alloy. Scr. Mater. 2018, 154, 192-196. [CrossRef]

33. Takahashi, T.; Minamino, Y. Ternary diffusion and thermodynamic interaction in the $\beta$ solid solutions of Ti-Al-Fe alloys at 1423K. J. Alloys Compd. 2012, 545, 168-175. [CrossRef]

34. Lu, J.; Ge, P.; Li, Q.; Zhang, W.; Huo, W.; Hu, J.; Zhang, Y.; Zhao, Y. Effect of microstructure characteristic on mechanical properties and corrosion behavior of new high strength Ti-1300 beta titanium alloy. J. Alloys Compd. 2017, 727, 1126-1135. [CrossRef]

(C) 2018 by the authors. Licensee MDPI, Basel, Switzerland. This article is an open access article distributed under the terms and conditions of the Creative Commons Attribution (CC BY) license (http:// creativecommons.org/licenses/by/4.0/). 